Revue internationale de l'économie sociale

Recma

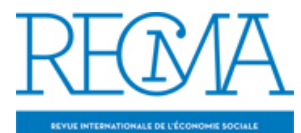

\title{
Bain de jouvence pour Jean Jaurès et Charles Gide?
}

\section{Jean-François Draperi}

Numéro 304, mai 2007

URI : https://id.erudit.org/iderudit/1021525ar

DOI : https://doi.org/10.7202/1021525ar

Aller au sommaire du numéro

Éditeur(s)

Association Recma

ISSN

1626-1682 (imprimé)

2261-2599 (numérique)

Découvrir la revue

Citer ce document

Draperi, J.-F. (2007). Bain de jouvence pour Jean Jaurès et Charles Gide ? Revue

internationale de l'économie sociale, (304), 4-4.

https://doi.org/10.7202/1021525ar d'utilisation que vous pouvez consulter en ligne.

https://apropos.erudit.org/fr/usagers/politique-dutilisation/ 


\section{BAIN DE JOUVENCE POUR JEAN JAURĖS ET CHARLES GIDE?}

(1) C. Gide, "L'école nouvelle", conférence du 28 mars 1890, in Cahiers BHESS, $\mathrm{n}^{\circ} 1$.

(2) Revue socialiste, janvier 1910, cité par Jean Gaumont, Histoire générale de la coopération en France, FNCC, 1924, t. II, p. 87.

(3) Cf. M. Pénin, " A la redécouverte de Charles Gide ", Recma, n²66, 1997 ; « Prolégomènes à une œuvre d'économie sociale: écrits de Charles Gide, 1869-1886 ", Recma, $\mathrm{n}^{\circ} 273,1999$; "Charles Gide ", L'économie sociale de $A$ à $Z$, Alternatives économiques, "Guide pratique ", 2006. a Recma se réjouit de publier pour la troisième année une sélection de contributions présentées aux Rencontres internationales du Réseau interuniversitaire de l'économie sociale et solidaire. Après les équipes marseillaise et grenobloise, c'est celle de Rennes qui coordonne les rencontres et présente ci-après la thématique retenue: «L'économie sociale et solidaire face à ses responsabilités " ( $p .9)$.

Ce numéro comprend par ailleurs un article important sur la relation entre le management et la santé des salariés. A partir d'une enquête auprès de 234 médecins du travail, Patrick Guiol et Jorge Muñoz montrent qu'un management autoritaire, de même qu'un mauvais climat social, a un impact sur la santé des salariés. Cette altération passe fréquemment par un déni de reconnaissance, dont les auteurs soulignent la prégnance. Les entreprises de l'économie sociale sont directement concernées par leurs conclusions et il serait intéressant de mesurer l'avantage comparatif qu'on leur prête et qu'ils vérifient au moins en partie à propos des Scop.

L'émergence de trois forces politiques inspirées par des pensées libérale, socialiste et social-chrétienne à l'issue du premier tour des élections présidentielles est l'occasion de rappeler qu'il y a un siècle, l'économie sociale s'est construite sur la base d'une alliance entre l'école socialiste et l'école chrétienne contre le libéralisme de Frédéric Passy.

Ce rapprochement est suggéré par Charles Gide dès 1890 : «Ce qui fait le fond même de la doctrine socialiste, à savoir la croyance à un ordre social possible très supérieur à l'ordre de choses actuel et appelé tôt ou tard à passer du domaine du possible dans celui du réel, est aussi le nôtre. [...] Nous croyons comme elle que [...] la lutte pour la vie [sera remplacée] par l'association pour la vie ${ }^{(1)}$. "Ce rapprochement devient effectif en 1912, par la fusion des deux grandes fédérations de coopératives, l'Union coopérative, présidée par Charles Gide, et la Bourse coopérative, animée par Jean Jaurès. Jean Jaurès, député à Albi et soutien décisif de la Verrerie ouvrière, s’était éloigné de l'analyse sociale de Marx à partir de 1887 et converti à la coopération dès 1889. Il affirme en 1910: "Lorsque trois actions sont aussi essentielles que le sont l'action syndicale, l'action coopérative et l'action politique, il est vain de régler entre elles un ordre de cérémonie et il faut les utiliser toutes les trois au maximum ${ }^{(2)}$."

Quant à l'économie sociale gidienne, elle poursuit quatre buts essentiels: procurer à chacun un minimum de travail pour un minimum de salaire, offrir les services essentiels (alimentation, logement, santé, récréation et éducation), permettre la prévoyance (l'assurance et l'épargne) et l'indépendance (le crédit, la petite entreprise) ${ }^{(3)}$. Ces propositions sont-elles si difficilement actualisables que l'économie sociale soit aussi peu apparue dans le débat politique?

Jean-François Draperi 